\title{
Bringing values back in: How purposes shape practices in coherent school designs
}

\section{Citation}

Mehta, Jal, and Sarah Fine. 2015. "Bringing Values Back in: How Purposes Shape Practices in Coherent School Designs." Journal of Educational Change 16 (4) (November): 483-510. doi:10.1007/s10833-015-9263-3.

\section{Published Version}

10.1007/s10833-015-9263-3

\section{Permanent link}

http://nrs.harvard.edu/urn-3:HUL.InstRepos:33063305

\section{Terms of Use}

This article was downloaded from Harvard University's DASH repository, and is made available under the terms and conditions applicable to Open Access Policy Articles, as set forth at http:// nrs.harvard.edu/urn-3:HUL.InstRepos:dash.current.terms-of-use\#OAP

\section{Share Your Story}

The Harvard community has made this article openly available.

Please share how this access benefits you. Submit a story.

\section{Accessibility}




\title{
Bringing Values Back In: How Purposes Shape Practices in Coherent School Designs
}

\author{
Jal Mehta and Sarah Fine \\ Harvard Graduate School of Education
}

Final Pre-Publication Version

2015

Published in

Journal of Educational Change

Official citation:

Mehta, Jal and Sarah Fine. 2015. "Bringing Values Back In: How Purposes Shape Practices in Coherent School Designs." Journal of Educational Change 16 (4): 483-510. 


\title{
Bringing Values Back In: \\ How Purposes Shape Practices in Coherent School Designs
}

\begin{abstract}
$\underline{\text { Abstract: }}$
Perhaps the most daunting challenge in building good educational systems is generating quality practice consistently across classrooms. Recent work has suggested that one way to address this dilemma is by building an educational infrastructure that would guide the work of practitioners. This article seeks to build upon and complicate this work on infrastructure by examining why two very different schools are able to achieve consistency of practice where many other schools do not. Findings suggest that infrastructure is not self-enacting and needs to be coupled to school level design in ways that are coherent and mutually reinforcing if infrastructure is going to lead to consistency of outcomes. At the same time, we find that the schools differ substantially in their visions of knowledge, learning, and teaching (purposes), which in turn imply very different kinds of organizational designs (practices). In conclusion, we suggest that the notion of infrastructure is plural rather than singular, and that different designs are appropriate for different pedagogical visions and social contexts.
\end{abstract}




\section{Bringing Values Back In: How Purposes Shape Practices in Coherent School Designs}

One of the most daunting challenges in building good educational systems is generating quality teaching practice consistently across the nation's many classrooms (Elmore 1996). Study after study reveals what American parents long have known: that teachers are the most important non-family input into students' academic successes, and that there is considerable variation in teacher quality from classroom to classroom (Sanders and Rivers 1996). Despite images of successful suburban schools and failing inner city schools, research consistently suggests that there is more variation among teachers within schools than across them (Rivkin, Hanushek, and Kain 2005).

Researchers and reform advocates advance two different interpretations of this reality. For some, it suggests that the American K-12 sector needs systems that can measure individual teacher's contributions to student outcomes, which can in turn allow administrators to identify weak teachers and remove them from the field. Others argue that the problem lies less in "teachers" than in "teaching" (Hill and Herlihy 2011), meaning that the field as a whole needs to develop certain features that would enable ordinary teachers to produce quality practice. David Cohen and his colleagues, in particular, argue that the major challenge is to build the kind of "infrastructure" that exists in other professions and that functions to create more consistency of practice across individual practitioners (Cohen and Moffitt 2009, Cohen 2011, Cohen and Bhatta 2012, Cohen et al. 2014, Mehta 2013a, Mehta 2013b). From this vantage point, the wide variation in instructional quality that exists within schools reveals that schools as organizations are weak interventions, lacking the kind of robust mechanisms that would produce more consistently strong practice from classroom to classroom. 
This paper seeks to explore this second point of view. While there has been considerable interest in the notion of "infrastructure" since Cohen and Moffitt suggested the term in 2009, there has been little research that unpacks what is meant by the term, and there have been only a few sustained inquiries into the conditions under which it might lead to greater consistency of practice across classrooms. This paper seeks to address this gap empirically by examining two high schools that have succeeded in achieving considerable consistency across classrooms. In the pages that follow, we explicate the norms, structures, processes, and materials that enable these schools to enact their visions, and use this to develop an argument about how these schools differ from other schools we studied which had larger gaps between their espoused values and their enacted practices. (Of course, whether realizing one's values more consistently is a good or bad thing depends on the values the school is seeking to realize and the ends by which it is being judged, a point we return to below.)

Specifically, we argue that the two focal schools share the following elements which enable them to enact their visions consistently across classrooms: 1) granularity of instructional vision; 2) thick mechanisms by which this vision is disseminated, including materials, coaching, feedback, and peer collaboration; 3) transparency such that what happened in each classroom is visible to the school as a whole; 4) symmetry in giving adults opportunities to learn in ways that parallel how students learn; 5) collective identity that infuses shared meaning and purpose to the work; and 6) an organizational design that integrates all of these elements into a coherent whole. While the two high schools are pursuing radically different missions — one was a "no excuses" college preparatory school and the other was an interdisciplinary project-based school—they share the above elements, and they shared a commitment to developing and maintaining a coherent design which enabled them to align their central structures, processes, and norms to 
produce the outcomes they sought. In offering this analysis, we seek to connect to and build upon the growing literature that emphasizes the importance of "coherence" as critical for effective school designs (Newmann et al. 2001, Honig and Hatch 2004, Bryk et al. 2010, Cobb and Jackson 2011, Cohen et al. 2014, Johnson et al. 2015), and to "thicken" the emerging literature on infrastructure.

At the same time, our research on these two schools reveals that they have adopted very different designs to achieve their very different purposes. In particular, what was notable about these schools is that their visions of knowledge, learning, teaching, students, teachers (purposes) are tightly aligned with their organizational structures (practices). One of the schools, No Excuses High (a pseudonym), embraces a deeply hierarchical vision in its core DNA. Knowledge is something which previous generations have defined and students need to assimilate, ends are clearly defined from the top, relationships are hierarchical, expertise flows downward from those in more senior positions to those in more junior roles, and tight control (of teachers by administrators, as well as of students by teachers) is the order of the day. Tasks, which feature traditional disciplinary academic content, are analytically challenging but tightly managed (i.e. short blocks with many carefully scaffolded steps, intended to ensure incremental progress towards disciplinary proficiency). The other, Dewey High (also a pseudonym), takes a much more egalitarian and open stance: ends are defined by teachers and students as much as administrators, relationships are peer to peer, expertise is less important than creating an ethos of mutual inquiry, and empowerment (of teachers by administrators, as well as of students by teachers) is the sine qua non of daily practice. Tasks are interdisciplinary, project-based, and develop over long periods with significant opportunities for students to create and, intentionally, also sometimes fail. 
For each school, all of these choices are guided by a vision of what is desirable for students: in the first case, to demonstrate proficiency of traditional disciplinary content in preparation for college; and in the second case, to undertake interdisciplinary projects through which students will learn content, develop skills, and come to see themselves as producers rather than simply receivers of knowledge. Each set of choices entails particular strengths as well as corresponding weaknesses.

These differences complicate the argument outlined above, suggesting that while building infrastructure and connecting it to a coherent design is critical to realizing aspirations in practice, there are also different kinds of infrastructure which are linked to distinct visions of what schools should be like and what students should know and be able to do. It is no accident that we have arrived at this argument in the year 2015. After a long period in which test scores were the only outcome by which schools were judged, recent years have seen a renewed interest in the variety of desirable ends for education beyond basic literacy and numeracy, including critical thinking, collaboration, personalized learning, social-emotional learning, and citizenship education, among others (Wagner 2008, Pellegrino et al. 2012, Mehta and Fine forthcoming, Levinson 2012). In this context, it is increasingly important to think about how infrastructure and design may need to vary to meet these varying ends. We argue that the next step for these debates is to wade into these messy and value-laden waters and to think about what kinds of design and infrastructure are socially and educationally desirable.

\section{$\underline{\text { Literature Review }}$}

The Importance of Infrastructure

When it comes to improving schools, reformers have long been divided between topdown and bottom-up perspectives. Top-down perspectives suggest that the core problem is 
variability across schools and teachers: variation in curriculum, funding, the distribution of teachers, and academic expectations produce inequalities for students. Proponents of this position frequently advocate for more top-down intervention in the form of resource and teacher (re)distribution, curricular standards, and performance accountability in order to remedy inequalities across schools and districts (Haycock and Hornbeck 1995). In contrast, bottom-up perspectives draw on the effective schools literature (Edmonds 1979, Purkey and Smith 1983) to suggest that good schools need autonomy in the form of control over budget, hiring, curriculum, and other key decisions (Hill 2013). Like those who favor top-down solutions, bottom-up proponents are often ardent advocates of equity, but they worry that top-down efforts often result in compliance-oriented activities which add little value and interfere with school-level efforts to develop coherence. They also argue that bottom-up approaches allow for more community input, enable needed pluralism across schools, and create opportunities for schools and communities to take more agency over their own schooling (Fung 2004).

When Cohen and Moffitt (2009, Cohen 2011: 56-64, Cohen and Bhatta 2012) introduced the notion of infrastructure, they suggested a third way in this debate. They argued that schooling, particularly American schooling, is missing a critical layer of resources that could organize and anchor the work of teaching. Included among these resources are an agreement upon what kinds of problems a profession can reasonably tackle and what results should be expected, agreed-upon standards and norms that inform judgments about the quality of work, materials and technology that guide the work in the field, and training and apprenticeships that induct new members and familiarize them with the agreed-upon standards and practices for the field. The American system, they argued, has some of these elements, but because of fears of excessive governmental control they are not organized or aligned-curriculum and assessments 
are often misaligned, teacher education is not linked to particular content or pedagogy because there is no agreement as to what that content or pedagogy might be, textbook publishers shape curriculum but with no connection to expected outcomes for students, and so forth. The widespread inconsistency that appears in American teaching, they argued, results from this absence of a significant force that could build this consistency. If such an infrastructure were in place it would be easier to empower school-level leaders and still have a reasonable expectation of consistent quality across schools.

In making this case, they drew together a number of strands that previously had been articulated but had not been integrated under a single umbrella. Lortie (1975) famously argued that teachers lack a shared technical vocabulary, and that the process of training is too short and weak to overwhelm the lengthy "apprenticeship of observation" that leads many teachers to teach as they were taught. Spillane et. al (2011) have argued that teaching lacks the kind of technical core that exists in other fields, and have drawn attention to the way that material artifacts influence the ways in which people teach. They also built on the earlier work of Cohen and Hill (2001) which showed that, under the right conditions, top-down reform can work if it provides significant opportunities for teachers to engage in ongoing learning in a way that is linked tightly to the content that they teach. Cohen and Moffitt (2009) also connected their work to a longstanding discussion about the problems of governance in American education (Fuhrman 1993), suggesting that the American fear of centralized control produces fragmentation. In these ways, the recent Cohen and Moffitt book picks up on the well-known Smith and O'Day (1991) paper, which argues for the need to use state standards-based reform as a way to coordinate and 
align the many actors across the system to build an integrated educational system within a federalist paradigm. ${ }^{1}$

In more recent years, Cohen and his collaborators have turned their attention to subgovernmental levels of education, arguing that charter networks and comprehensive school reform design models are the place where one can see a more developed infrastructure than has thus far been possible in states or districts. Their work on these networks, particularly on Achievement First (Rosenberg 2012), Success for All (Peurach 2011), and America's Choice (Glazer 2005) are cautiously optimistic. In a book looking across these networks, Cohen and his colleagues (2014) suggest that these networks need to solve puzzles of design, implementation, improvement, and sustainability, each of which requires a significant effort for the central entity to work with its local sites to develop the kind of instructional infrastructure and organizational support for that infrastructure that will enable it to work in practice. Many of the specifics of what is described in this work are consistent with the notion of infrastructure as initially theorized.

Particularly pertinent to this paper, in this most recent book Cohen et al contrast the approach of Success for All and America's Choice with the work of Accelerated Schools. While all three sought to develop networks of schools, Success for All and America's Choice were relatively "tighter" in their mechanisms of control, seeking to develop the materials and other guidance for the programs within their centralized hubs (informed by the work in the field); Accelerated Schools, by contrast, believed that letting schools do their own design work was

\footnotetext{
${ }^{1}$ The creation of the Common Core creates the potential for building such an infrastructure, in that it creates common standards which could guide the creation of assessments, teacher education, curricular materials, professional development, and other elements needed for an aligned system. Cohen and Bhatta (2012) argue, however, that, thus far, this is more potential than reality, and that substantial investments will need to be made in building infrastructure if Common Core is to achieve its promise.
} 
important for developing sufficient staff commitment and buy-in. External formal evaluations showed greater effects on standardized measures for the more tightly controlled networks (Correnti and Rowan 2007), a finding which supports the contention that in the absence of an externally developed detailed infrastructure, schools are likely to falter or be inconsistent in their practice.

\section{From Infrastructure to Coherent Design(s)}

If the notion of infrastructure provides a critical set of resources for guiding instructional improvement, there is still the question of what conditions need to be present to successfully enact this infrastructure. This requires us to link the discussion of infrastructure to questions about school, network, or system-level design.

At the school level, an initial set of answers about the needed conditions for success comes from the literature on effective schools (Edmonds 1979, Purkey and Smith, 1983). This work has consistently posited that "effective" schools need certain core ingredients: a baseline level of student safety and order, high expectations, opportunities for teachers to collaborate and learn, use of data to improve practice, and, in some versions, the right to make core decisions over budget, personnel, and curriculum. What is absent from this earlier literature is an account of how these processes connect to the instructional core - the triangle between teacher, students and curriculum that affects what a student learns and how (City et al. 2009).

More recent work by Bryk et al. (2010) links together the holistic perspective offered by the effective schools literature with the more focused emphasis on the instructional core. They argue that developing professional capacity and an "instructional guidance system" (which is akin to what Cohen and collaborators call infrastructure) are critical components in academic success, but that they need to be part of an integrated package of school supports if they are to 
achieve their ends. These supports are school leadership, professional capacity, parentalcommunity ties, a student-centered learning climate, and instructional guidance. This work builds on the now sizable literatures on professional learning communities (e.g. Wenger 1999, Dufour 2007), relational trust (e.g. Bryk and Schneider 2002), organizational learning (e.g. Senge 1990, Louis 2005), and instructional leadership (e.g. Leithwood et al. 2004), suggesting that an integrated set of supports must be present for school improvement to occur. It also, rightly in our view, suggests that infrastructure must be linked to a set of school-level organizational processes if the infrastructure is going to be successfully enacted.

The Bryk et al. (2010) work also connects to a larger literature on the importance of "coherence" for effective schooling. In a world of fragmented governance and limited resources, coherence promises a way to align structures, processes, roles, and systems in ways that enable needed focus and align available assets towards educational improvement. While scholars have noted a variety of reasons why coherence is difficult to achieve in practice (Honig and Hatch 2004), it remains an attractive ideal at the school (Bryk et al. 2010, Newmann et al. 2001), network (Cohen et al. 2014), district (Supovitz 2006, Cobb and Jackson 2011, Johnson et al. 2015), and system (Smith and O'Day 1991, Cohen and Moffitt 2009) levels.

While many of these scholars have identified specific practices that they think need to be aligned for educational improvement (e.g. the Bryk et al. 2010 model of five supports), one of the powerful features of coherence as an aspiration is that there are different ways it can be achieved (Johnson et al. 2015). Coherence is part of a larger class of contingency theories (Lawrence and Lorsch 1967), a branch of organizational theorizing which suggests that effective organizational design varies depending on the nature of the task, the skill level of the workers, and other features of the internal and external environment (Daft 2010). In a world that has urban 
schools and rural schools, project-based schools and "no excuses" schools, Catholic schools and independent schools, large consolidated high schools and small themed academies, International Baccalaureate schools and vocational schools, the key question for coherence theorists is less what practices bring about coherence and more what features need to be aligned to achieve a particular mission in a particular environment.

\section{Pedagogical Orientation}

While a number of features can and should factor into the development of school designs, we argue that the notion of instructional purpose deserves particular attention. At a fundamental level, in a coherent school design everything must connect back to a vision of what happens in a good classroom. As Cobb and Jackson (2011: 7-8) point out, while it is clear that instructional vision is at the heart of good design, discussing the nature of good instruction has been surprisingly absent from the literature:

Research on large-scale instructional improvement has traditionally been the province of educational policy and educational leadership. While much can be learned from these studies, most of this work does not take a position on what counts as high-quality teaching but instead operationalises it in terms of increasing student test scores irrespective of the quality of the tests. In the course of our work... it has become increasingly evident that views on what counts as high-quality mathematics teaching matter when formulating strategies or policies for instructional improvement.

Why might this be the case? To oversimplify, imagine a continuum from traditional to progressive pedagogy. On the traditional side, one might imagine that students are seen as novices and that teachers are seen as experts whose role is to support their charges in mastering pre-established bodies of knowledge and associated skills. On the progressive end, one might imagine that students and teachers are viewed as partners in mutual inquiry, with the main goal being for students to discover and make meaning of existing knowledge as well as to create new knowledge. Neither of these approaches is inherently better or worse, but it is reasonable to 
imagine that they imply different kinds of infrastructure and design in order to be enacted consistently across classrooms.

In particular, much of the research on infrastructure has been developed in the context of studying "no excuses" charter networks as well as Success for All—organizations which have traditional visions of their educational goals as well as fairly prescriptive methods for achieving them. There is not a parallel research strand focused on progressive schools or networks. While practitioners like Deborah Meier and Ted Sizer have written about their own schools (Meier 2002) and about desirable attributes for progressive schools in general (Sizer 1984, Sizer 2004), there has not been formal research on the infrastructure and design which supports effective practice within such schools. Our analysis of Dewey High seeks to begin to fill this gap.

\section{$\underline{\text { Research Questions and Methods }}$}

Building on the discussion above, our analyses sought to explore the following research questions:

1) What are the major elements that support schools in consistently enacting practices that match their espoused values? What structures, norms, materials, routines, and other elements are important in developing successful infrastructure and design?

2) Does the nature of infrastructure and design vary across schools with different pedagogical orientations? If so, which elements of infrastructure and what kinds of designs support more traditional pedagogy, and which support more progressive pedagogy?

To answer these questions, this paper draws on data from a long-term ethnographic study of 30 high schools (Mehta and Fine, in progress) that seek to engage students in higher-order cognitive processes such as analysis, knowledge utilization, and creation (Bloom 1956; Marzano and Kendall 2007). These schools were selected though a multi-pronged sampling process, including examining lists of high-performing high schools, using snowball sampling to identify schools 
seeking to engage students in these higher-order processes, and sending out a survey to a variety of policymakers, researchers, charter network leaders, and other knowledgeable actors to nominate leading schools. We were particularly attentive to seeking different kinds of variation in the sample, so we consciously sought schools that varied in their size, pedagogical orientation, and whether they operated as traditional public schools or charter schools. We also deliberately over-sampled schools serving primarily high-poverty students, although we included in our sample several socio-economically integrated schools, and a small number of schools serving more affluent populations.

For this paper, we examined two schools that ranked among the most successful in our sample when it came to consistently realizing their visions in practice. One of these schools, No Excuses High (a pseudonym) is a charter high school located in a Northeastern city. All of the students in this school qualify for free and reduced price lunch, and more than 90 percent are African American and Latino. The pedagogy in this school is heavily based on the "gradual release of responsibility" model of instruction (Pearson and Gallagher 1983), and classes are tightly micromanaged. The school has been exceptionally successful by conventional metrics, far surpassing state averages on reading and math tests, and sending all of its graduates to four year colleges. The other school, "Dewey High" (a pseudonym) is a project-based urban charter high school in a Western state. The school is socio-economically diverse, using a zip-code-based lottery system to ensure even representation from both poorer and more affluent districts within its cachement area. Forty percent of its students are the first in their family to go to college; they are joined by the sons and daughters of doctors and lawyers. Its pedagogical emphasis is on helping students engage in interdisciplinary projects; blocks are frequently 90 minutes and many classes are team-taught by teachers from different disciplines. It too is quite successful by 
conventional metrics, scoring in the top 20 percent of the state on the math and reading test score index, and also sending most of its graduates to four-year colleges. The school also boasts a number of artifacts (field guides, science projects) that have become national models for projectbased work.

We conducted more than 200 hours of observation at Dewey High and 125 hours at No Excuses High. We wrote extensive narrative field notes of each class we observed. Since the goal was to inductively capture varying pedagogical approaches, we chose not to use a preexisting rubric or framework to organize our classroom observations but instead drew on our training as ethnographers to holistically capture what passed during a class session, including what the teacher was doing, what the students were doing, and the particular forms of discourse that transpired (Emerson, Fretz, and Shaw, 1995). Since we were particularly interested in efforts to foster cognitively demanding instruction, we paid careful attention to the task in each classroom; not just what task the teacher assigned or described in their plans, but what task the students were actually engaged in (City et al. 2009). As both schools were fairly small, we were able to see classes of at least 80 percent of the teachers at each school, and we attended full classes for each teacher.

To complement the observations, we conducted in-depth interviews with 20 teachers per school, as well as talking with relevant administrators and parents and hosting student focus groups. We interviewed 50 respondents at Dewey High and 40 at No Excuses High. Interviews ranged in length from 30 minutes to 90 minutes; with some administrators and focal teachers we did multiple interviews. We also examined artifacts of various sorts (classroom materials, student work, teacher planning guides) in an effort to develop a 360-degree picture of the instructional approach and the infrastructure guiding the work at each school. We developed initial hypotheses 
out of our early observations, and used grounded theory (Glazer and Strauss, 1967) to guide some of our questions and choice of later observations. In particular, at each school, we sought to identify what was distinctive about their overall approach and then we sought to collect additional information that would allow us to investigate those strands in greater depth. For example, at Dewey High, we decided to follow the development of a small number of projects from beginning to end in order to better understand the arc of how these projects developed. We sought to balance these deep dives against the broader picture that emerged from the school through interviews, observations, and artifact analysis. All data were entered into a qualitative software program (Atlas.ti) and were coded, drawing on both our developing conceptual framework (etic codes) as well as themes that emerged from the data (emic codes) (Seidman, 2006; Weiss, 1994).

These data allowed us to speak to some questions but not others. We could not evaluate the causal impact of these schools on outcomes; while both of these schools do extremely well on standard outcomes, we have no way of assessing the unique contribution of the schools to these results, in comparison to family background, student motivation, or other characteristics. What we could assess is that, by comparison to many of other schools in the study, these schools had much less of a gap between their espoused theories of action and their enacted practice. Since at these schools and many of the others in our sample we were able to see a large crosssection of classes, we were able to see whether what happened in these classrooms consistently matched what their leaders said they were aiming to do. Despite the fact that we sought to intentionally sample for schools that were known for pursuing higher order cognitive processes, the dominant pattern in most of the schools in our sample (both charter and traditional public) was one of wide inconsistency of instructional quality from classroom to classroom, with little 
imprint of school, district, or network-wide efforts to improve pedagogy (Cohen, 1989; Mehta and Fine, in progress). No Excuses High and Dewey High distinguished themselves from this group by being the rare schools in which enacted practice matched espoused goals, and thus why they are the focus of this article on the elements of effective infrastructure and design. ${ }^{2}$

We used process tracing (Mahoney 1999) to identify the mechanisms and processes that allowed these schools to achieve the enacted practice that they had proposed. We gave particular credence to selected mechanisms when they were mentioned by multiple groups of interviewees (such as by both administrators and teachers) and when they were corroborated by our own observations of these mechanisms in practice, effectively triangulating our data. We also drew on our larger sample of schools as a corpus of comparison cases that demonstrate what happened when these processes are not in place.

Finally, it is important to note that both focal schools are relatively small (fewer than 400 students in each), and that as charters they are afforded some freedoms (particularly in their hiring and use of budget) which facilitate the development of the coherent structures. Achieving similar coherence would be more difficult and potentially take different forms in larger comprehensive high schools. At the same time, since we were seeking to study innovative practices, we intentionally focused on schools that had the freedom to innovate. It is also worth stressing that these were a number of other charters in our sample which had similar freedoms but were much less successful in achieving their espoused values than the schools we discuss here.

\footnotetext{
${ }^{2}$ Also, note that because the data we collected was cross-sectional rather than longitudinal, we cannot speak to the question of how these schools originally developed the designs that we identify here. For more on the relationship between design, implementation, improvement, and sustainability, see Cohen et al. (2014).
} 


\section{No Excuses High}

No Excuses High is part of a well-known network of "no excuses" charters. All of the work at the school is anchored around a single goal—preparing every student academically to gain admittance to a four-year college - and a single instructional vision-assuring that each enrolled student is successful on a series of external exams that certify readiness for college-level academic content. As described earlier, the school achieves this vision: the school consistently scores at the top of the state in percentage able to demonstrate proficiency on state math and reading exams; the students frequently score $4 \mathrm{~s}$ and $5 \mathrm{~s}$ on advanced placement tests, and routinely 100 percent of graduates attend college.

\section{Space, Time and Human Resources}

The school achieves these results by taking a social engineering viewpoint on the question of generating consistency of practice across classrooms. The enemy, from the point of view of the administration, is unplanned variation on the part of either students or teachers. For students, this means a system of tight behavioral control to ensure that they are continually putting forth effort and that instructional minutes are fully utilized. For teachers, it means the organization-wide development of curricula, lesson plans, and other materials, as well as an intense system of training, observation, and feedback focuses on the rapid development of less experienced teachers. As the principal reports, “My greatest fear is randomness - we don't tell teachers you and just come here and teach. This is not about idiosyncratic teaching about your autobiography. It's about very deliberate lesson planning, very deliberate instructional leadership." As we will explain in more detail below, these systems have drawbacks as well as advantages, but, compared to other schools in our sample, they produce a high level of consistency of instruction across classrooms. 
At No Excuses High, the traditional subjects—math, science, English, and historycomprise the core part of each student's diet. Faculty are organized into departments, and the department chair is responsible for closely overseeing the work that his or her teachers undertake. This oversight takes several forms. The first is in developing curriculum. It is the goal of the school to develop a curriculum for each grade and subject, something that is created by the department chair and other experienced teachers and is vetted through effective use with actual students. As the principal says, "Once a curriculum is finished, it's pdf-ed. It's done... we are happy with it." The development of such a curriculum is what Rosenberg (2012), in her study of Achievement First, calls a "safeguard": it seeks to ensure that what happens in a particular classroom matches the goals of the organization.

Experimentation with new approaches is not something that the organization wants individual teachers to attempt; rather it is the planned province of the department chairs. As one administrator describes it, "We only encourage our veterans to do the experimenting - our new teachers are under pretty tight rules. They're not supposed to deviate from the standards and exemplars we've set for them." We witnessed one interview for the hiring of a new teacher where the teacher was told by the principal (during the interview) that his instruction, at least for the first few years, would not be his own but would be the province of the department chair. In a meeting between the interviewee, the department chair and the principal, the principal told the prospective teachers that he was going to hold the chair accountable for the new teachers' instruction, and that it was the prospective teachers' job to listen and do everything the department chair said. New teachers are hired, a number of our respondents told us, more for their attitude than their know-how; the school seeks candidates who are willing to listen and are quick studies. The school also shies away from the word "coaching" because it implies that the 
person being coached makes the final decisions; instead, actors refers to coaching as "instructional development."

New teachers go through several days of summer training that are run by the instructional team at the network level, where they are introduced to the school's basic pedagogical approach and the series of moves that they are expected to use in the months and years to come. This induction experience is followed by weekly cycles of feedback. In a typical week, an instructor is observed by the department chair on Monday, debriefs that observation on Tuesday, and meets on Wednesday or Thursday to discuss lesson plans for the following week (drawing in part on the feedback from the past week). Then on Sundays, all teachers who are not department chairs are required to send in the week's lesson plans by 2 p.m. to the department chair, and they receive them back with comments and notes by 8 p.m. New instructors and department chairs are also frequently assigned the same room, which means that new teachers grade papers and prepare lessons at a desk in the back of the room while more experienced teachers in their subject areas are teaching, and, conversely, department chairs have informal opportunities to observe many more lessons than are formally observed while they are doing their work.

The sum total of these various processes mean that teachers receive roughly $25-30$ rounds of observation and feedback over the course of the year from experienced mentors who teach same-age students in the same subjects. The teachers almost uniformly describe this process as incredibly valuable, and we saw a number of teachers in the spring of their first year who were much more able to do what No Excuses High wanted of them than first year teachers we saw in other schools. As one young teacher describes it, "Other schools of thought think that teaching is this thing that happens by osmosis... we feel that you don't have time to waste and 
you can get better fast. Teaching isn't magic - at least not most of it. The way we do that is by codifying good teaching."

The nature of this feedback process is also carefully structured and internally studied by the school. Feedback sessions are themselves videotaped and studied for ways to increase the efficacy of the feedback. When multi-faceted problems are identified, they are broken into smaller parts so they can be worked on gradually. As one department chair describes the process, "It's important to establish the philosophical underpinnings in what we're doing [in these conversations with teachers]. It can be too procedural if we're not - teachers need to feel respected as intellectuals." Then you say, "What can we do about it?" You list out options, usually more than what you can do in a single week and so you break it out. Then you stay on it in different forms. At a certain point it recedes from the headline status."

The school recognizes that the primary challenge of this approach is that the teachers who are being "developed" need to take ownership of what they are learning if it is to work. As one department chair said, "[The issue is that teachers] are trying to imitate, not translate" the techniques and systems that the school is training them in. He added, 'Kids know when you're just doing when you're supposed to be doing. That's one of the grave errors in these types of schools... district schools don't have this problem, they have the opposite [where too many teachers are teaching by force of personality only.]" Similarly, newer teachers describe gradually recognizing that despite the heavily prescriptive feedback offered to them, they need to figure out ways that they could comfortably inhabit the pedagogical system in which they are working in order to have credibility with the students.

Classrooms themselves couple intense regimens of behavioral control with a carefully structured pedagogical template. Behavioral control of students is enforced through many of the 
same mechanisms that have been described in previous studies on "no excuses" schools - an emphasis on maintaining proper posture and tracking the speaker, a practice of correcting even minimally disengaged behaviors, and a homework bin into which students need to place all of their homework at the beginning of the day (to ensure that students don't try to complete it while they were in class). One day of our research was on the third to last day of school in June, and the emphasis on not wasting a single minute of class-time was fully intact; we saw literally every minute of that day used on instructional time, just as in the other 15 days of our research. Administrators and teachers justify this intense behavioral control as necessary for students who are academically behind; they do not have a minute to waste, they argue, and these systems enable everyone to focus almost entirely on instruction.

\section{Pedagogy, Norms, and Culture}

The pedagogy of No Excuses High is structured around an "I do/we do/you do" template - the language associated with the gradual release of responsibility model (Pearson \& Gallagher 1983). Classes generally feature a "do now," which is a task that links the homework to the objective of the day, then a short model lesson from the teacher, and then a series of opportunities for students to practice in short timed blocks. Countdown timers on smart boards oversee virtually every minute of each class; at any moment in the day you can see time ticking down from seven or ten minutes to zero. Contrary to images of traditional classrooms featuring lengthy teacher talk and students taking notes, the primary metaphor here is more akin to athletic notions of the importance of practice; if students aren't doing the work, chances are that they aren't learning it, the teachers told us. Analytically, the tasks are often quite hard: "The period from 1880 to 1930 was one that prioritized the public interest; the period from 1930 to 1980 prioritized the private interest. Is this statement true, with respect to economics, culture, and 
politics?" But the way in which students pursued these tasks is quite carefully managed - in the class featuring that task, students were then given graphic organizers, asked to label the two periods in columns, to put the dimensions in rows, then to fill in the six boxes, and then to reach a conclusion, and debate it with a partner, all in 12 to 15 minutes.

More broadly, the idea is that school is about a fixed body of knowledge in the core disciplines, which frequently needs to be split up into hundreds of core sub-pieces, each of which students need to encounter and show mastery. Each student is formatively assessed on each set of targeted skills, and then re-tested in short intervals to track progress. When students struggle with a particular task, they do it again with gradually diminishing support until they can independently demonstrate proficiency. Teachers, for their part, are both supported and assessed on whether their students are mastering these pieces of knowledge, receiving extensive feedback from colleagues or coaches on each sub-dimension of their practice.

Thus, there is considerable symmetry (Roberts 2012) in all facets of this organizational and pedagogical structure, meaning that there are clear parallels in the approaches to adult and student learning. The core assumptions are that both teachers and students need to be controlled; that expertise is something that is possessed by those at the top; that improvement comes through careful practice and feedback from those who are more expert to those who are less expert; and that the primary goal is to eliminate random variation in both how teachers teach and what students know.

At the same time, this vision also has some tradeoffs: namely that it delimits the ability of either students or teachers to connect their work to their own interests, and to be creative in addition to rigorous. One teacher worried, for example, that, "We do control instruction so carefully that sometimes I worry that it doesn't provide enough opportunity for students to 
explore... Sometimes I think our students don't have the opportunity for intellectual curiosity." Students are similarly positive about the overall mission of the school and the ways in which it is delivering on its promise to get them ready for college, but feel that, as one put it, "there isn't enough personal liberty... the structures and boundaries are too extensive. There is no freedom of speech and that the staff doesn't take into consideration what the students want." Similarly, among the staff, first and second year teachers effusively praise the intensity of the feedback structure, but third and fourth year teachers grate at not having their ideas heard and continuing to be treated as if they were novice teachers.

\section{Dewey High}

More so than any other school in our sample, Dewey High, a 15-year-old urban charter in southern California, represents a deliberate attempt to move away from the conventional vision and values associated with schooling. As a result, visitors to the school often find the experience of being there to be initially disorienting. The building itself, a sprawling one-story space full of light and glass, feels like a cross between a science museum and a tech startup. Wandering through the halls and peering into classrooms, one is likely to encounter a broad range of activities, the majority of which involve producing and/or performing original work: a class of students rehearsing a historical drama that they have written following their study of the Renaissance; a pair of students roving the halls in search of people to interview for their documentary film on contraception distribution; trios using Photoshop to edit images they took while recently exploring a local watershed; a student learning to use a soldering iron while his partners finalize plans for a robotic toy; an administrator serving as an impromptu audience member and critique partner for a student who is preparing for her upcoming "presentation of learning"; a class returning from a morning-long expedition to find and analyze local graffiti; and 
so on. There are no bells, no lockers, no textbooks, no strict rules about being in the hallways, and a relatively small amount of whole-group instruction-teachers spend far more time circulating and conferring with groups than giving directions or demonstrations at the board. Throughout, the teaching and learning takes on a quality that is often informal and exploratory, encompassing improvisation and play as well as "serious" discussions and academic study.

Although the life unfolding at Dewey High sometimes can appear to border on chaotic, it is in fact the product of a highly intentional design - a design rooted in a fundamental reimagining of the purposes and processes of schooling. This reimagining, which both looks backward to the beliefs of Dewey and forward to the rapidly changing realities of the twenty-first century, can be broken into several strands. First, the school pushes back against what its founders believe to be unproductive boundaries by pursuing "the three integrations": bringing together students from different backgrounds, integrating cognitive and manual work, and linking academic work to the world beyond. Second, in the tradition of its (imagined) namesake, Dewey High embraces an uncertain and "part to whole" vision of how knowledge is generated, challenging the traditional notion that the role of the teacher is to transmit a static and preestablished corpus of knowledge into the minds of his or her students (Cohen, 1989). Finally, and perhaps most radically, Dewey High strives to cultivate an ethic of contribution in its learners, treating them as creative agents with the capacity to produce work that has authentic personal, social, and aesthetic value. Schooling is thus repurposed not only as an investment in the future, but as a vehicle for transformative experience in the present (Mehta and Fine, 2012).

The story of how and why the founders of Dewey High arrived at this distinctive vision is beyond the scope of this article. What we can say is that the fact that these founders embarked on the design process for the school with such clear convictions, and that they so carefully 
considered how these convictions could serve as the basis for decisions about infrastructure, together form a critical reason that the school has been able to achieve such unusual consistency of quality across classrooms. Below, we explore more deeply both the school's overall design and its core infrastructure, positing that it is the way in which the latter are framed and driven by the former that allows Dewey High to accomplish what so many other schools have struggled to do.

Space, Time, and Human Resources

Dewey High's founders recognized from the outset that pursuing a different set of goals would requires rethinking schooling's core organizational "grammar" (Cuban 1993). Everything from lockers and bells to academic departments and final exams was on the table for reconsideration - and, as the above description suggests, the vast majority of these features did not survive unscathed. Instead, the school is set up to support project-based endeavors that are collaborative, interdisciplinary, flexibly structured, and sustained over long periods of time. The most obvious sign of this reorganization is the school's physical plant. The "commons" area at the center of the building serves by turns as a student lounge, a theatre, a staging-area for large projects, and an auditorium. Although most classrooms do have doors and walls, almost all have large glass windows on multiple sides, and it is not unusual to find students, teachers, and administrators in rooms other than their own, observing each other at work. The walls, for their part, are adorned with polished student-made artifacts that represent the fruition of past projects. Finally, the building's many doors are often propped open throughout the day, a visible sign of the school's commitment to integrating schoolwork with the broader world as well as of the trust that it places in students. 
This trust, along with the commitment to integrating traditionally disparate subjects, plays out in how time is structured as well. Blocks at Dewey High are in theory two hours long, but the days often play out as they do in some elementary school classrooms: bells do not dictate the flow of work and if a given group of collaborating teachers decide to sustain a given activity longer, to change when and who is leading instruction at a given time, or to take students offcampus, there is ample latitude to do so. At a more macro level, the semesters at Dewey High are punctuated by not only end-of-project exhibitions, where groups of students present their work to peers, teachers, parents, and community members, but also by "presentations of learning" where individual students present, defend, and reflect on the previous semester's learning in order to prove that they are ready to move on. Mirroring this more formalized commitment to flexibility is the constant ebb and flow of productivity that characterizes the days at Dewey. "Some days we're doing projects and going psycho... other times we're just walking around the school talking to people," one freshman girl describes. Like so many of the school's features, this is no accident. While teachers do not celebrate wasted time, they recognize that a certain amount of unevenness in terms of productivity is the inevitable result of giving students real latitude, and many of them explicitly connect this stance to the rhythms of professional life. "Project time doesn't divide itself neatly into hours of the day," one administrator says. "Deadlines loom and you see incredible bursts of energy and activity, and deadlines pass and there are lulls - just like you see with adults."

The school's reorganization of human resources is not as immediately obvious as its reorganization of space and time, but it is equally important. For teachers, working at Dewey High means that instead of teaching alone and occasionally meeting in subject-alike departments, they enter into yearlong partnerships (sometimes trios) that bring together disparate disciplines: 
biology with media arts, humanities with Spanish, math with physics and carpentry, and so on. With ongoing support provided by colleagues, these teams co-plan and co-teach semester-long projects that sit at the intersection of their interests and areas of expertise. In some cases, each member of a teaching team takes on distinct pieces of the project; in others, co-teachers choose to blend their roles more fully, taking the lead when it makes sense. Regardless of the form that the collaboration takes, the belief is that teachers together will create richer projects than they would do on their own. To that end, teachers with more experience often partner with those newer to teaching or to the school, creating apprenticeship-style relationships where novices gain skill by participating under the guidance of veterans. While some of these collaborations end in frustration, they more often produce powerful learning; many teachers report that working with more experienced colleagues is a critical part of how they acclimated to the norms, processes, and standards of the school.

Students, for their part, hail from virtually every part of the city due to a zip-code-based lottery system. They are organized into grade-level teams of fifty and assigned to a primary set of collaborating teachers for the year. By design, each of these teams includes students that run the gamut in terms of race, socioeconomic status, special needs, and prior achievement. In keeping with first of the school's "three integrations," teachers treat this diversity as an asset and a source of learning, often assigning students to partners that they would not have chosen themselves. Given the sustained nature of the projects, these assignments are no trivial matter. Like their teachers, students have to learn to play to each other's strengths, to manage and persevere through conflict, and, ultimately, to produce work that represents a productive blend of their ideas and skills. In some cases this process results in surprising friendships-bonds that transcend boundaries of race, class, geography, and personality. In other cases it is less 
successful, but, at least in the eyes of the school, this too results in important learning outcomes. As one eleventh-grader reflected, "Working with other people is something that is important not only because it can help build your character... but also because it prepares you for working with coworkers and other people later on."

\section{Pedagogy, Norms and Culture}

One of the most strikingly distinctive qualities of Dewey High, a quality which is rooted in its underlying ethic of contribution, is its celebration of divergence. Rather than trying to codify and disseminate a school-wide curriculum, the school operates around the belief that teachers do their best work when they are conceptualized as designers or craftsmenprofessionals whose work reflects their unique perspectives and skills. This leads to projects that are often startlingly divergent from each other; students in one eleventh-grade science classroom might be learning genetic sequencing while those next door are building robots. This also means that when teachers acquire new interests or new teaching partners, their projects evolve accordingly. While the most successful endeavors are sometimes repeated from year to year, innovation is prized; "standardized" is all but a dirty word. Symmetrically, the same principle holds true for students, who, within the parameters and expectations of quality for each project, are encouraged to produce work that reflects original creative thinking grounded in their and their partners' distinctive interests and strengths.

One might assume that this approach would produce exactly the kind of unevenness from classroom to classroom that so many schools struggle to overcome-and if one thinks about learning outcomes as mastery of specific content and related sub-skills, it does. Dewey's leaders would be the first to acknowledge that the school's students do not graduate having all studied the French Revolution, having read Hamlet, having mastered the basics of Newtonian physics, or 
having completed pre-calculus mathematics. What they do share, leaders argue, however, is a powerful set of shared dispositions, paired with an eclectic but consistently deep working knowledge of a variety of topics and fields. As one of the founders explains:

The fact that students don't graduate with the same skills doesn't bother me, because all students do exhibit their work, all students do design and build, and all students do undergo a transitional presentation of learning where they reflect upon the work they've done, their strengths and their needs, and their hopes moving forward. That's the common intellectual mission.

Even assuming that one has accepted this unique way to think about Dewey High's goals, however, the question remains: how does the school ensure that projects, as divergent as they are in terms of modality and content, share a consistent level of depth and rigor? What spells the difference between productive divergence and problematic unevenness?

The answers to this question lie in the plethora of interconnected ways by which the school's vision of excellence is made visible to members of the community. This plethora begins with the answer to a question that Dewey High's leaders insist is critical: what do the walls say? As suggested earlier, walking into the school-building is a deeply aesthetic experience. It is barely an exaggeration to say that all available wall-space, including that of the bathrooms, is covered in student-produced artifacts. These things fill the space with a sense of color and life, but they also communicate a great deal about the institution's distinctive qualities: the value placed on the production of original artifacts, the emphasis on making learning visible and public, and, perhaps most important in terms of ongoing utility within the school, the standards of quality to which learners are held. To newcomers, the effect is often immediate. As one teacher describes of her initial interview for a teaching position, "I walked into the school knowing next to nothing about it, but then I saw the [playground-sized wooden suspension bridge]... Just seeing that these kids who were not gifted kids were making things like that was 
enough to make me want to work here." For students, the constant reminder of what their peers produce is a more powerful motivation to do their best work than any grading rubric; it communicates with unwavering clarity that they can and are expected to produce work that holds its own in the public eye.

Dewey High's distinctive walls are complemented by a number of other forms of transparency_forms which together create a densely interconnected system by which the school's standards of excellence are communicated. The glass walls and open-door policies throughout the building mean that members of the community often witness each other at work. Exhibitions and presentations of learning are staggered so that students, teachers, and staff can participate as audience-members alongside invited guests. Digital portfolios, which staff and students are required to keep up-to-date with written, photographic, and/or video records of their work, allow community members (and other interested parties) to keep track of what projects are underway and help teachers to track their students' progress. Teachers also get a glimpse at each other's projects on Wednesday mornings, when they meet in groups to look together at student work and help each other refine their plans. Finally, teachers are encouraged to describe and reflect on their work in articles for a journal which often lies open on desks and in common areas.

These processes do more than just establish standards of quality; they also help to maintain them. As one veteran teacher reflected, “There's a very clear message that it's not okay to play the fool here... nobody wants to be the one with nothing to show when people are going to see your work." The lack of a specific reference to "teachers" or "students" here is intentional. The prospect of public embarrassment is particularly aversive to adolescents, but teachers, too, find the realities of peer observation and public exhibition to be motivating - nobody wants to be 
the one whose students are presenting hand-drawn posters of the solar system when their colleagues' classes have published books or designed interactive exhibits for the local science museum. A friendly sense of competition, again true for students and teachers alike, helps to shore up this commitment to excellence. "There's this sense that you're always trying to design the most badass project," one teacher reports. The trace of ruefulness in his voice suggests that this pressure can feel burdensome, but teachers argued that it is certainly better than the inverse - the apathy that sets in when teachers and learners toil in isolation, lacking the momentum generated by knowing what they are aiming to produce and understanding the standards against which their work will be judged.

Similarities: Granularity, Thickness, Transparency, Symmetry, Collective Identity, and Coherent Organizational Design

There are a number of similarities between the two schools that help to explain why they have been more successful than others in our sample in consistently realizing their instructional visions.

First, they both have a granularity in their visions of instruction, which is to say that administrative leaders, teachers, and students shared a highly developed picture of what they thought good instruction looked like, and that this picture served as the anchor for much of what happened at these schools. At No Excuses High, it is grounded in the "I do/we do/you do" template, the use of micro timers, and frequent formative assessments; at Dewey High it is grounded in project-based explorations culminating in exhibitions. It is difficult to overstate the difference here between these two schools and many of the other schools in our sample, where there was no clear granular vision of what good instruction would look like. 
Second, both schools have thick mechanisms for adult learning in their theories of change. At No Excuses High, this is instantiated through giving novice teachers a curriculum to work off of, and then using repeated rounds of carefully constructed feedback from department chairs in their subjects to stimulate improvement. No Excuses High's theory of adult learning draws heavily on analogies from sports and the studies of expertise, emphasizing the role of repeated practice on specific elements of instruction as a way to build teachers' skills. Dewey High similarly places adult learning at the center of their model, but in a very different way. Teachers are frequently paired across disciplines to work on projects, which provides a way for newer teachers to learn from more experienced teachers about how to construct high quality projects. Dewey High also preserves weekly time for teachers to engage in shared learning opportunities, although these often function in a more reflective and holistic mode than No Excuses High's emphasis on the practice of discrete skills.

Third, both schools have highly transparent structures that make visible the quality of teachers' and students' work on instructional content. At No Excuses High, this is accomplished through the relentless sharing of student achievement data, which is publicly shared and monitored by the principal and other instructional leaders. Teachers are highly aware of how students are faring as reflected in these data, which are highly connected to how they are viewed within the school and ultimately whether they will be retained. While schooling may be a multifaceted endeavor, there is no ambiguity at No Excuses High about the metrics on which teachers and students are expected to succeed. There is similar clarity, if around a very different vision, at Dewey High. Exhibitions are highly public showings of students' work, and by implication, of the projects that the teachers design and manage. Status among teachers is allocated on the basis of the creativity and quality of the projects that students had developed, which creates some 
pressure among teachers to annually develop new ideas for projects. The administration takes the highly unusual step of explicitly telling teachers that their students are expected to get 70 s but not 100s on the state tests, which unambiguously signals the schools' priorities for what would count as good teacher and student work.

Fourth, both schools have created considerable symmetry (Roberts 2012) that links the learning experiences of adults to those of children. At No Excuses High, much as student work is broken down into discrete pieces of knowledge and sub-skills, adult feedback follows a similar pattern. There is conscious attention among department chairs that feedback should be specific, actionable, and not overwhelming; rather it should focus on one teaching strategy or area of improvement at a time, moving on only when teachers demonstrate proficiency on that technique. At Dewey High, much as students are collaborating to develop interdisciplinary projects, teachers are similarly trying out ideas on one another across disciplines, trying to figure out what combinations of content and deliverables might catch with students. Dewey High also has a number of people who are practicing members of the fields that they are trying to teach students—graphic designers teaching graphic design, writers teaching writing, etc. —and they are strongly encouraged to continue to pursue these passions as ways to keep themselves fresh and generate new ideas for students. Finally, both adult learning sessions and student learning are heavy on notions of reflection as a critical tool for self-assessment and growth.

Fifth, both schools have sought to cultivate a collective identity that anchors and gives meaning and purpose to the schools' activities. At Dewey High, the projects anchor the identity; other schools would strive to do well on state tests, this school is different, one where students made things and demonstrated their values through exhibitions. From the founder to the principal to the teachers and the students we heard the same refrain: this school is intentionally different, 
we want to make things which matter, this is a school for "dorks" or "nerds" who actually care about school and the things that can be created there. Some parents are less sanguine about the vision, as they worried about whether their students would succeed by conventional markers, but almost everyone we talked to inside the school was committed to the school's ideas. No Excuses High sought to build a collective identity around its exceptional performance on standardized tests and college acceptance rates; in lieu of athletic pep rallies, it held rallies to celebrate the performance on these state exams. Culturally, we also heard many of its members speak with pride about the hard work that everyone put in to achieve these results, and boundary drawing about how this school was different from regular public schools where teachers asked little of students and students put little into school. No Excuses High has more difficulty getting full buyin to its vision, particularly among older students and more experienced teachers, who occasionally wondered in interviews with us whether there could be more to school than preparation for tests or college, and, in particular, the somewhat grim workmanlike atmosphere was a source of critique for some. Even so, it is clear that everyone associated with No Excuses High takes pride in being a part of the school and the results that it produces.

Sixth and finally, as important as each of these individual elements was the way in which at each school they fit together as seamlessly designed environments. Structure, culture, and instructional vision are tied together into an integrated package. Specifically, at No Excuses High the vision of instruction is about disciplinary mastery, which anchors all of its other practices and structures. There is a congruence of purpose for everyone in the building, as it is clear that performance on these external assessments, along with college acceptance, was the singular purpose of No Excuses High. Dewey High is similarly aligned but to very different ends. The commitment to sustained interdisciplinary inquiry and the frequency and visibility of exhibitions 
organizes much of the energy and effort in the building, and also provides the primary source of accountability for both students and teachers. The visible display of work on the walls, the relaxed attitude towards time, and the hiring of people with real world experience in professional domains all build an atmosphere of school as "start-up" rather than as factory. The repetition of public performances and of having to design and carry out projects created enabled students to become increasingly confident public speakers and experienced project designers. This culture also served to habituate new students to the norms of the school.

Relatedly, both schools are also very clear about what they are not doing. Much as it is said that "strategy is as much about what you say no to as what you say yes to," these schools are as clear about what they would not let in as what they would. Neither school has much in the ways of athletics. In the spirit of a carefully designed and intentional curriculum, No Excuses High does not welcome unplanned experimentation by teachers and there was no ambiguity on this point. Dewey High is firm about their lack of respect for conventional metrics (e.g. standardized tests), which enables teachers to focus singularly on developing more authentic and lively learning experiences that are directly situated in what would be interesting to students.

\section{Differences: How Purposes Shape Practices, and Why Coherence is Context Dependent}

While there is much that was in common about the two schools, their basic differences in mission and values (purposes) are deeply interwoven in the nature of their very different organizational designs (practices).

At No Excuses High, both purposes and practices are shaped by a deeply hierarchical vision of epistemology and social organization. The knowledge that students are supposed to master exists in disciplines, and has been derived by experts (e.g. Newton, Darwin) of previous generations. The role of the school is to transmit that knowledge until students demonstrate 
proficient understanding of it. Active processing may be encouraged, but the core facts and concepts have been previously established. Students primary job is to get into college (more ambitious learning may come in college or beyond), and the schools' primary job is to help students demonstrate disciplinary proficiency so that they will be able to do so.

From this vision also follows a certain definition of the problem and a certain design to remedy that problem. If the goal is to get all students to achieve disciplinary proficiency as measured by external exams, then the problem is unplanned variation and idiosyncrasy from teacher to teacher. From this problem definition everything we see at No Excuses High follows: the effort to "pdf" the curriculum; the extensive feedback cycles for teachers; and the effort to resist "innovation" as a threat to developing well-oiled and consistent machinery. This design also creates and legitimates a hierarchical organizational structure-much as students have their learning structured for them by their more knowledgeable teachers; young and newer teachers have much of their learning structured for them by their more expert colleagues.

This vision has some clear strengths. A sympathetic read of what happens at No Excuses High would liken it to how people are trained to play classical instruments: lots of disciplined practice overseen by people who are more expert in the domain. Such an approach features hierarchy and considerable control, but this level of control actually increases the learner's agency, as development of knowledge and technique gradually makes one more competent in the domain. Interviews with first and second year teachers and first and second year students (freshman and sophomores) supported this view, as they both said that the level of direction was extremely helpful in clarifying focus and building considerable knowledge and skill. The results of No Excuses High are a testament to the power of this organizational model. 
At the same time, there are some tradeoffs inherent in this vision of epistemology and social organization. Epistemologically, it assumes that all knowledge that high school students might study has been previously derived by others, as well as that the lessons that teachers can teach and the moves that they should make have been previously created by their superiors. Organizationally, it assumes that people on top always know best, and that people should be implementing the vision created by their superiors. The problems with this vision are the flip side of its strengths: few opportunities for creativity, few connections between academic work and students' identities or real world concerns, and consistent meeting of floors but few opportunities to reach for ceilings. Concretely, more experienced teachers and students chafe at the regimens of control, and neither students nor teachers could point to assignments or pieces of student work of which they are really proud. It also inspires more extrinsic than intrinsic motivation, as the clear message for everyone is that schoolwork is something to be endured now for a payoff later.

The Dewey High case quite consciously takes the opposite view of epistemology and social organization. As we've seen, there is a strong emphasis on students as producers and not simply consumers of knowledge, as students' consistently make videos, documentaries, books, field guides, and a range of other products that they hope others will use. Disciplines are deemphasized, both by combining core classes (from English and History to Humanities) and by organizing around projects or problems that are interdisciplinary or transdisciplinary in their orientation. In all of these respects, Dewey High seeks to disestablish conventional authorities, and empower their students and teachers to transgress boundaries in their pursuit and production of knowledge.

Organizationally, teachers at Dewey High are similarly emboldened as creators of teaching practice. The organizational structure is much flatter than at No Excuses High, with 
teachers having a central role in decision-making of all sorts. In terms of teaching itself, teachers are responsible for developing their own lesson plans and in particular their own projects; teacher as designer is a central tenet of teaching at Dewey High. This has the advantage that teaching can be much more closely tailored to the contexts of particular students and contemporary events, as teachers are constantly trying to develop projects that will catch students' interests in the particular moment. Zooming out, there is much more in common here with the modes of social organization that have been widely valorized in the business literature since the 1980s (e.g. Peters and Waterman 1982); namely that the role of management is to empower frontline practitioners, who are more likely than their superiors to possess the kind of detailed practical and tacit knowledge that is needed for effective practice. The role of the higher layer of hierarchy, in this vision is to provide the kind of "infrastructure" that would enable the sharing of this knowledge, as well as to organize the overall social enterprise in a way that aligns goals, eliminates unnecessary distractions, and allows skillful frontline practitioners to best use their talents. You could call this second vision infrastructure as well, but it is a very different kind of infrastructure than the one that is instantiated at No Excuses High.

As at No Excuses High, the Dewey High vision had strengths as well as tradeoffs. The strengths are that it empowers teachers and students as designers of their own learning, which often gave the work a kind of palpable energy and momentum. That Dewey High linked this empowerment with a highly transparent set of student outputs (the projects) for which both teachers and students are accountable enabled the school to build some consistency across classrooms even in the context of a more decentralized structure. At the same time, the schools' commitment to group-based projects meant that it was less able to pay attention to how each student was mastering each skill, as was the case at No Excuses High. It did have mechanisms in 
the way that it scaffolded its projects to ensure that all students participated in the creation of the final project, but there was not the same kind of intensity of each student, each subject, each skill, that we saw at North Star. If No Excuses High was trading off the opportunities to reach for "ceilings" in its pervasive effort to ensure that each student met "floors", Dewey High was creating many opportunities for every student to reach ceilings, but was less attentive to ensuring that each student achieved a floor in each subject.

There is also the question of the contextual factors that enable each of these visions. Dewey High, by virtue of its strong reputation and opportunities for teacher autonomy and design, has a large teacher pool to pick from; it also has high levels of teacher retention which meant that their need for new teachers was relatively small. They also are working with a socioeconomically diverse group of students, which means that many of their students enter with the kind of cultural capital that the school draws heavily upon in building student support for its progressive orientation. In this context, with a relatively experienced teaching force and a group of students' who are inclined towards its vision, its approach of setting clear expectations, providing opportunities for adult collaboration and learning, and otherwise getting out of teachers' way was a good fit for their teaching population and was compatible with their overall egalitarian orientation. There is also a kind of positive vicious cycle operating here; by building the kind of conditions where good teachers actively want to work, they are able to create high levels of retention and good practice, which makes it easier not to have to hire really inexperienced teachers, which supported a design which required high levels of initiative and knowledge by teachers.

Conversely, No Excuses High is working within a "no excuses" model which places incredibly high demands on teachers (extremely long hours, Saturday school), where it expects 
teachers to work within carefully prescribed lesson templates, and where it strong values teachers' willingness to buy-in to the school's vision and practices. Those factors, coupled with the school's location in a highly depressed urban area, leads the school to hire many first and second year teachers, many of whom are part of Teach for America or other alternative certification programs. Additionally, more than 90 percent of the students receive free or reduced price lunch and many entered the middle school two or more levels behind grade level, meaning that there need to be intensive efforts to catch them up in core subjects. The combination of these factors leads to a highly prescriptive approach to both teacher and student training, which yielded consistent practice on the part of teachers and strong showings on conventional metrics on the part of students. There is, however, also a kind of vicious cycle operating here as well—novice teachers appreciated the level of direction and feedback, and students who were in their first year or two at the school appreciated the kind of order and classroom rigor that was absent from their previous schools. But as teachers became more experienced, they begin to resent the level of prescription and control and were disheartened by the lack of opportunities to develop their ideas; similarly, students who were in their third or fourth year at the school were chafing at its limits and asking for more authentic work. Many of these teachers and students left the school, which, in turn, seemed to reinforce the model; with high levels of staff turnover and many first and second year teachers, the highly directive model fit well within the assumptions of its paradigm.

\section{$\underline{\text { Discussion and Conclusion }}$}

This research has implications for the concept of infrastructure. Most directly, it suggests that infrastructure is not self-enacting (Cohen and Bhatta 2012). Even in No Excuses High's case, where there was a highly developed set of codified materials, these materials are only able 
to achieve their impact because they are part of a consciously designed environment that built these materials into all aspects of their schools' structures. Many of the cases that Cohen and his colleagues have studied are of networks that have consciously managed the various elements of the system to develop these integrated wholes (Cohen et al. 2014); the findings of this study are consistent with that research. But if the hope is that by developing good infrastructure, run of the mill schools will be able to generate consistency of practice, our research suggests a more pessimistic conclusion; only if the infrastructure is part of a coherent, designed, and integrated structure will it achieve its effects (Newmann et al. 2001, Bryk et al. 2010, Cobb and Jackson 2011, Cohen et al. 2014, Johnson et al. 2015).

A related point is that the notions of infrastructure and coherent design have thus far not been sensitive enough to issues of the context in which they will be used. As these cases reveal, different visions of infrastructure and design are likely appropriate depending on the skill and experience level of the teachers who will be using them, as well as the vision of knowledge and social organization into which they are embedded. Much of the initial work on infrastructure has assumed relatively inexperienced and unskilled teachers; this research suggests that a different form of infrastructure is likely appropriate for more experienced and skilled teachers. Infrastructure is not a single, but a plural notion, and part of what remains to be explored is what variants of infrastructure and what kinds of coherent designs might be appropriate in what contexts.

Developing this more pluralistic vision of infrastructure and design will also require much more explicit acknowledgement of the question of educational values. Supporters of "infrastructure," "effective schools," "professional learning communities," and "data-driven instruction," have championed those concepts in ways that make them seem value-neutral, which 
has been useful in enabling researchers to claim objectivity, and schools and programs to claim public dollars without the appearance of bias. But this research suggests that the foundation for any kind of educational success is having a very explicit vision of what good educational practice looks like, which inevitably requires taking a stand on the value-laded questions of the nature of good education. Hence we suggest that future work on infrastructure more directly embrace this question of how purposes shape practices, stating explicitly what vision of education a particular vision of infrastructure is rooted in.

There is also the question of whether certain features of the focal schools shape the larger conclusions that can be drawn from them. Clearly, the ability of these two schools to achieve coherence is facilitated by their charter status - they have the ability to hire and fire their faculty, manage their budget and their curriculum, and they have student populations that had elected to be there. They are also relatively small in size. These factors are not sufficient for success-we saw many other charters in our study that had similar freedoms but were unable to realize their espoused values in practice — but they are helpful in enabling skilled school leaders to enact their visions.

Even so, there may be ways to transport these lessons into more traditional settings. In our research on large comprehensive high schools, we find that they are too large and what is asked of them too varied for them to realize the kind of unitary vision we see at No Excuses or Dewey High. But it is possible for these schools to create programs or departments within schools that are internally coherent, as well as to develop intentional mechanisms for responding to the diversity of imperatives they are trying to fulfill (Mehta and Fine, in progress). Another possibility is that policy can facilitate the creation of smaller more mission-driven schools, or more districts could embrace the portfolio model, which enables schools to make more of the 
kinds of decisions that charters can make (Bulkley 2010). A third possibility is that the district seeks to develop at the district level the kind of coherence we saw here at the school level; this has been a successful approach in places like Montgomery County (Childress et al. 2009) and Long Beach (Austin et al. 2004). Any of these paths can generate consistent high quality instruction, but, if the schools we studied here are any indication, they will be successful only if they can integrate a granular vision of instruction with a coherently designed system that is sensitive to their context and aligned to their values. 


\section{$\underline{\text { Citations }}$}

Austin, J., Schwartz, R., \& Suesse, J. 2004. Long Beach Unified School District (A): Change That Leads to Improvement (1992-2002). (PEL-006). Boston, MA: Harvard Business School Publishing.

Bloom, Benjamin. 1956. Taxonomy of Educational Objectives: The Classification of Educational Goals. New York: D. McKay.

Brown, Tim. 2009. Change by Design: How Design Thinking Transforms Organizations and Inspires Innovation. New York: Harper Business.

Bryk, Anthony et al. 2010. Organizing Schools for Improvement: Lessons From Chicago. Chicago: University of Chicago Press.

Bryk, Anthony and Barbara Schneider. 2002. Trust in Schools. New York: Russell Sage Foundation.

Bulkley, Katrina, et al., eds. 2010. Between Public and Private: Politics, Governance and the New Portfolio Models for Urban Reform. Cambridge: Harvard Education Press.

Childress, Stacey et al. 2009. Leading for Equity. Cambridge: Harvard Education Press.

City, Elizabeth, Richard Elmore, Sarah Fiarman, and Lee Teitel. 2009. Instructional Rounds in Education: A Network Approach to Improving Teaching and Learning. Cambridge, MA: Harvard Education Press.

Cobb, Paul \& Kara Jackson. 2011. "Towards an Empirically Grounded Theory of Action for Improving the Quality of Mathematics Teaching at Scale." Mathematics Teacher Education and Development, 13(1), 6-33.

Cohen, David K. 1989. "Teaching practice: Plus que ca change...." In P. W. Jackson (Ed.), Contributing to Educational Change: Perspectives on Research and Practice (Berkeley, CA: McCutchan, (pp. 27-84).

Cohen, David K. Teaching and Its Predicaments. Cambridge, MA: Harvard University Press, 2011.

Cohen, David K. and Monica Bhatta. 2012. "The Importance of Infrastructure Development to High-Quality Literacy Instruction.” The Future of Children 22(2): 117-138.

Cohen, David K and Heather Hill. 2001. Learning Policy: When State Education Reform Works. New Haven: Yale University Press.

Cohen, David K., and Susan L. Moffitt. 2009. The Ordeal of Equality: Did Federal Regulation Fix the Schools? Cambridge, MA: Harvard University Press. 
Cohen, David K. et al. 2014. Improvement by Design: The Promise of Better Schools. Chicago: University of Chicago Press.

Correnti, R. and Rowan, B. 2007. "Opening up the black box: Literacy instruction in schools participating in three comprehensive school reform programs." American Educational Research Journal, 44, 298-338.

Cuban, Lawrence. How Teachers Taught: Constancy and Change in American Classrooms, 1890-1990. New York: Teachers College Press, 1993.

Daft, Richard. 2010. Organization Theory and Design. $10^{\text {th }}$ edition. Mason: South-Western Cengage Learning.

DuFour, Richard. "Professional Learning Communities: A Bandwagon, an Idea Worth Considering, or Our Best Hope for High Levels of Learning?" Middle School Journal 39, no. 1 (2007): 4-8.

Edmonds, Ronald. "Effective Schools for the Urban Poor." Educational Leadership 37, no. 1 (1979): 15.

Elmore, Richard. 1996. "Getting to Scale with Good Educational Practice." Harvard Educational Review, 66 (1): 1-26.

Elmore, Richard. School Reform from the Inside Out: Policy, Practice, and Performance. Cambridge, MA: Harvard Education Press, 2004.

Emerson, R.M., Fretz, R. I., \& Shaw, L.L. (1995). Writing Ethnographic Fieldnotes. Chicago: University of Chicago Press.

Fuhrman, Susan, ed. 1993. Designing Coherent Educational Policy: Improving the System. San Francisco: Jossey Bass.

Fung, Archon. 2004. Empowered Participation: Reinventing Urban Democracy. Princeton: Princeton University Press.

Glaser, Barney and Anselm Strauss. 1967. The Discovery of Grounded Theory: Strategies for Qualitative Research. Hawthorne: Aldine de Gruyter.

Glazer, Joshua. 2005. Eduational Professionalism: The Development of a Practice-Centered Frame and Its Application to America's Choice School Design. Ph.D. dissertation, University of Michigan.

Haycock, Kati, and David W. Hornbeck. "Making Schools Work for Children in Poverty." In National Issues in Education: Elementary and Secondary Education Act, edited by John F. Jennings. Washington, DC: Phi Delta Kappa International, 1995.

Hill, Heather and Corinne Herlihy. 2011. "Prioritizing Teacher Quality in a New System of Teacher Evaluation." Education Outlook, American Enterprise Institute. 
Hill, Paul. 2013. Strife and Progress: Portfolio Strategies for Managing Urban Schools. Washington: Brookings.

Honig, Meredith \& Thomas Hatch. 2004. "Crafting Coherence: How Schools Strategically Manage Multiple, External Demands." Educational Researcher 33 (8): 16-30.

Johnson, Susan Moore et al. 2015. Achieving Coherence in District Improvement: Managing the Relationship Between Districts and Schools. Cambridge: Harvard Education Press.

Lawrence, P.R., Lorsch, J.W. 1967. Organization and Environment: Managing Differentiation and Integration. Boston: Harvard University

Leithwood, Kenneth; Louis, Karen Seashore; Anderson, Stephen; Wahlstrom, Kyla. 2004. "How Leadership Influences Student Learning". The Wallace Foundation.

Leithwood, Kenneth et al. 2002. Second International Handbook of Educational Leadership and Administration. Boston: Kluwer Academic Publishers.

Levinson, Meira. 2012. No Citizen Left Behind. Cambridge: Harvard University Press.

Lortie, Dan C. Schoolteacher: A Sociological Study. Chicago: University of Chicago Press, 1975.

Louis, Karen. 2006. "Changing the Culture of Schools: Professional Communities, Organizational Learning and Trust." Accessed at: http://pdfs.scarecroweducation.com/SC/TJS/SCTJSLSep2006.pdf

Mahoney, James. "Nominal, Ordinal, and Narrative Appraisal in Macrocausal Analysis." American Journal of Sociology 104, no. 4 (1999): 1154-1196.

Manna, Paul and Patrick McGuinn. 2013. Educational Governance for the Twenty-First Century: Overcoming Structural Barriers to Reform. Washington, D.C.: Brookings.

Marzano, Robert and John Kendall. 2007. The New Taxonomy of Educational Objectives. Thousand Oaks: Corwin.

Mehta, Jal. 2013a. The Allure of Order: High Hopes, Dashed Expectations and the Troubled Quest to Remake American Schooling. New York: Oxford University Press.

- 2013b. "From Bureaucracy to Profession: Remaking the Educational Sector for the $21^{\text {st }}$ Century." Harvard Educational Review, 83(3): 463-488.

Mehta, Jal and Sarah Fine. 2012. "Teaching Differently ... Learning Deeply.” Phi Delta Kappan 94(2): 31-35.

Mehta, Jal and Sarah Fine. In Search of Deeper Learning: Inside the Effort to Remake the American High School, book manuscript, in progress, under contract with Harvard University Press. 
Mehta, Jal and Sarah Fine. Forthcoming. The Why, What, Where, and How of Deeper Learning in American Secondary Schools. Students at the Center, Deeper Learning Research Series. Boston, MA: Jobs for the Future.

Meier, Deborah. In Schools We Trust: Creating Communities of Learning in an Era of Testing and Standardization. Boston: Beacon Press, 2002.

Fred M. Newmann, BetsAnn Smith, Elaine Allensworth and Anthony S. Bryk. 2001. "Instructional Program Coherence: What It Is and Why It Should Guide School Improvement Policy." Educational Evaluation and Policy Analysis 23 (4): 297-321

Pearson, P. D., \& Gallagher, M. C. 1983. The instruction of reading comprehension. Contemporary Educational Psychology 8: 317-344.

Pellegrino, James et al. 2012. Education for Life and Work: Developing Transferable Knowledge and Skills in the $21^{\text {st }}$ Century. Washington: National Academy Press.

Peters, Thomas and Robert Waterman. 1982. In Search of Excellence: Lessons from America's Best Run Companies. New York: Harper and Row.

Peurach, Donald. 2011. Seeing Complexity in Public Education: Problems, Possibilities, and Success for All. New York: Oxford University Press.

Purkey, Stewart C., and Marshall S. Smith. "Effective Schools: A Review." Elementary School Journal 83, (1983): 426-452.

Rivkin, Steven, Eric Hanushek, and John Kain. 2005. "Teachers, Schools, and Academic Achievement." Econometrica. 73:2: 417-458.

Roberts, John. 2012. Instructional Rounds in Action. Cambridge: Harvard Education Press.

Rosenberg, Seneca. 2012. Organizing for Quality in Education: Individualistic and Systemic Approaches to Teacher Quality. Ph.D. Dissertation, University of Michigan.

Sanders, W. L., \& Rivers, J. C. 1996. Cumulative and Residual Effects of Teachers on Future Student Academic Achievement. Knoxville: University of Tennessee Value-Added Research and Assessment Center.

Seidman, I. (2006). Interviewing as Qualitative Research. New York: Teacher's College Press.

Senge, Peter. 1990. The Fifth Discipline: The Art and Practice of the Learning Organization. New York: Doubleday.

Sizer, Theodore R. Horace's Compromise: The Dilemma of the American High School. Boston: Houghton Mifflin, 1984.

- The Red Pencil: Convictions from Experience in Education. New Haven, CT: Yale University Press, 2004. 
Smith, Marshall S., and Jennifer A. O'Day. "Systemic School Reform." In The Politics of Curriculum and Testing: The 1990 Yearbook of the Politics of Education Association, edited by Susan Fuhrman and Betty Malen, 233-267. New York: Falmer Press, 1991.

Spillane, J.P., Parise, L.M. \& Sherer, J.Z. (2011). "Organizational Routines as Coupling Mechanisms: Policy, School Administration, and the Technical Core." American Educational Research Journal: 48(3): 586-620.

Supovitz, Jonathan. 2006. The Case for District-Based Reform: Leading, Building and Sustaining School Improvement. Cambridge: Harvard Education Press.

Tucker, Marc. 2011. "Standing on the Shoulders of Giants: An American Agenda for Education Reform." Accessed at: http://www.ncee.org/wp-content/uploads/2011/05/Standing-onthe-Shoulders-of-Giants-An-American-Agenda-for-Education-Reform.pdf.

Weiss, R. (1994). Learning from Strangers: The Art and Method of Qualitative Interview Studies. New York: the Free Press.

Wagner, Tony. 2008. The Global Achievement Gap. New York: Basic Books.

Wenger, Etienne. 1999. Communities of Practice: Learning, Meaning, and Identity. Cambridge: Cambridge University Press. 